\title{
Amours clandestines. Sociologie de l'extraconjugalité durable
}

\author{
Marie-Carmen Garcia (2016) \\ Lyon, Presses universitaires de Lyon, coll. "Sexualités " 280 pp.
}

\section{(1) Karina Felitti CONICET / IIEGE}

En la Argentina, los debates previos a la aprobación del matrimonio igualitario en 2010 y del nuevo Código Civil, que entró en vigencia en 2015, auspiciaron la discusión política y social sobre el contrato conyugal, sus características, propósitos y problemáticas.1 Uno de los resultados de estas deliberaciones fue que la infidelidad y el adulterio dejaron de considerarse causales de divorcio, eliminando un motivo que penalizaba con más rigor a las esposas que cometían esta "falta" que a los maridos. La modificación de esta normativa tuvo lugar en un contexto de agudización de los cambios en los roles y relaciones de género, y los modos de entender el amor, el erotismo y el sexo. Un factor importante es la constatación de una mayor longevidad que hace posible recomenzar la vida sexoafectiva, muchas veces, a partir de las innovaciones en materia de salud y la oferta de productos y servicios que proponen extender la juventud y el vigor sexual. La mayor aceptación del divorcio permite nuevos emparejamientos, mientras que el "amor libre" - proclamado por anarquistas y otras expresiones libertarias a fines del siglo XIX y las primeras décadas del XX- se extiende como propuesta, inquietud o práctica entre personas que no necesariamente se reconocen politizadas. Entre ellas surgen pactos en los cuales la honestidad y la franqueza son valores más importantes que la exclusividad sexual y/o amorosa.

Ante estas posibilidades -matrimonio por elección, divorcio, parejas abiertas, poliamor- resulta llamativo, y para muchos moralmente reprobable, que quienes asumieron al contraer matrimonio la exclusividad sexual opten por el simulacro, el silencio y la mentira cuando no pueden cumplirla; que en lugar 1. Sobre este tema, véase Hiller, R. (2017). Conyugalidad y ciudadanía. Disputas en torno a la regulación estatal de las parejas gay lésbicas en la Argentina contemporánea. Buenos Aires, Teseo. de separarse o plantearlo abiertamente, sostengan en paralelo a sus relaciones legales y públicas otras de tipo clandestino. El libro de la socióloga MarieCarmen Garcia se ocupa precisamente de ellas, de las relaciones extraconyugales durables que mantienen varones y mujeres heterosexuales en la Francia contemporánea. Para Garcia, ellas forman un sistema particular de adulterio o de infidelidad que, más que responder a una situación de crisis, se erige como un "modo de vida ordinario". Su estudio plantea un abordaje que evita aquellas explicaciones psicológicas que suelen ver a las personas infieles como seres patológicos o con una disposición especial. Por el contrario, propone que existe una interdependencia entre la relación conyugal y la extraconyugal, y establece los vínculos que ambas traman con una determinada ideología de familia y modelos de socialización de género.

Para conocer de cerca estas experiencias, Garcia relevó testimonios publicados en seis blogs de Internet de/para casados/as y otras plataformas, y a su vez contactó a personas involucradas en una relación heterosexual extraconyugal, que debía tener más de dos años de duración y estar sostenida con encuentros sexuales regulares y frecuentes. Fueron en total 23 entrevistas en profundidad, realizadas en persona y con seguimientos por teléfono y correo electrónico durante un lapso de cuatro años, tiempo que le permitió conocer el transcurrir de esos vínculos. De este conjunto se recortan las voces de 14 mujeres -algunas solteras o divorciadas-y de 9 varones - todos casados-, de entre 42 y 90 años, de clase media, de una tercera generación de nacidos/as en Europa, salvo una mujer cuya familia proviene del norte de África. Las historias y biografías de estas personas forman los dos apéndices de la obra, mientras que 
el planteamiento del problema de investigación y sus bemoles se presentan en la Introducción. Allí, la autora explica la necesidad que tuvo de generar confianza y mostrar empatía -contrariamente a la objetividad que suele recomendarse-, aunque esto no impidió que algunos/as le solicitaran no grabar las conversaciones ni tomar notas.

El libro se divide en cinco capítulos. Los dos primeros -1. "Explorar los amores clandestinos" y 2. "La fabricación de la heterosexualidad" - retoman otros estudios que analizan el amor y el matrimonio, dando cuenta de la escasez de trabajos sobre el amor por fuera de la pareja. Apoyada en algunos estudios de caso y un marco teórico amplio, Garcia aporta a una "sociología de la extraconyugalidad durable" que permite, al mismo tiempo, repensar el matrimonio. En una discusión con autores que destacan la estabilidad y satisfacción que otorga la conyugalidad, Garcia se ubica con quienes reponen la conflictividad de la institución matrimonial, cuestionan que sea siempre electivo y denuncian la violencia que enfrentan muchas mujeres en ella. Estudios históricos y sociológicos le permiten confirmar la persistencia de algunas representaciones, como la disociación de la mujer esposa y la mujer sexual, y del imperativo de alto rendimiento para los varones, especialmente en aquellos de mediana edad, obsesionados por el futuro y dispuestos a sostener varias relaciones al mismo tiempo “mientras el cuerpo rinda”. La socialización de género que auspicia estas prácticas propone también desigualdades en las relaciones extraconyugales. Por ejemplo, si el varón es casado y la mujer es soltera, ella suele ser más joven y estar en una situación económica más desventajosa, justamente por su edad y género. Las mujeres entrevistadas no quieren "perder el tiempo" e imaginan una vida conyugal futura con el amante, mientras que la mayoría de los varones encuentran satisfacción en esa clandestinidad, en esa "doble vida".

Estas dinámicas diferenciadas se analizan con detalle en los capítulos siguientes. En el capítulo 3, "Amores viriles", los entrevistados son citados valorizando la disponibilidad sexual -en cuanto al tiempo (acomodarse a sus horarios) y prácticas (BDSM, sexo anal y oral, porno, juguetes) - de sus amantes. Para varios, las imágenes contrapuestas de la madre y la puta siguen estando presentes. Esto no es ajeno a algunas amantes que llegan a sentirse como "putas gratis", lo que hace aflorar un sentimiento de humillación y de reconocimiento de que su poder está anclado en su agencia sexual y en su capacidad de esforzarse. Saben que lo más estratégico es no demandar nada y estar siempre disponible, pero esto tampoco asegura la continuidad de la relación. Y si bien la mayoría de los varones aquí analizados suelen decir desde el inicio que no van a separarse, muchas mujeres, especialmente las más jóvenes, esperan que sí lo hagan; quieren ser presentadas a los amigos del amante, salir del anonimato y usufructuar las condiciones de lo lícito: llamar por teléfono sin reparos, salir sin esconderse, tener sexo en el domicilio de él. Los varones solteros que se relacionan con mujeres casadas suelen tener prácticas diferentes. No suelen pensar en ese vínculo como una pareja, ven a otras mujeres en paralelo y hasta salen de vacaciones con ellas. Cuando las amantes salen con otros varones, en general las moviliza menos el deseo que la búsqueda de autoestima y el no estar pendiente del amante.

"Resistencias y sufrimientos femeninos" es el título del capítulo 4, en donde se analiza la "gestión de la dependencia": el problema de la adicción al amante, de la relación asimétrica, la sensación de humillación ante la espera, lo que implica padecer un tipo de sufrimiento que no suele generar empatía ya que "no está bien acostarse con el marido de otra”. ¿Por qué entonces se quedan en estos vínculos? Para algunas, transgredir la norma de la exclusividad sexual es una forma de reapropiarse de sus cuerpos, de vivir una situación "alocada" y rediseñar su feminidad. Además, la expectativa de la separación las hace vivir la relación como una historia de "amor romántico", en tanto ellas son las mujeres elegidas, el "verdadero amor", y las esposas un error que ellos revertirán al separarse. Con el transcurrir del tiempo, algunas comienzan a considerar que la espera es un sacrificio sin retorno ya que él - siendo "fiel" a lo anunciado al comienzo del vínculo- no dejará a su esposa. Las mujeres casadas, en cambio, suelen terminar poniéndoles fin a sus matrimonios para encontrar coherencia. Ellos, por el contrario, no ven incompatible que coexistan dos modelos de mujer, la madre y la puta. Estas situaciones diferentes son, para Garcia, la expresión de desigualdades sobre las que es necesario profundizar, ya que permiten ponderar cómo se da la autonomía femenina, la gestión de la libertad, en un mundo en donde los varones siguen teniendo el control.

Como se describe en el capítulo 5 - “La familia ante todo"-, los varones afirman que no quieren dejar de acompañar de cerca el crecimiento de sus hijos, ni tampoco abandonar el rol de esposo protector, papel que los hace pensarse como "fieles en la infidelidad". Aquí también juega un papel clave la socialización de género que los ha ubicado como jefes de familia. En este punto se enfrentan una socialización masculina y una femenina, una construida en el rol de proveedor y una femenina que, cuando se rebela, se 
vuelve autónoma, separada del rol maternal, pero dependiente en cuanto al amor, siendo funcional al modelo de amor romántico. Las historias seleccionadas no permiten saber qué sucede cuando también nacen hijos de estas parejas clandestinas, un tema que queda pendiente, lo mismo que las opiniones de las esposas y esposos "engañadas/os", su propia versión de la pareja.

Las relaciones extraconyugales, según Garcia, ponen en primer plano la naturaleza sexuada del matrimonio y su ideal de estabilidad. La durabilidad que propone la conyugalidad parece llevarse mal con el "amor pasión” tan valorado en el escenario de sexualización de la cultura actual. Los y las infieles parecen, al decir de la autora, resolver individual e implícitamente esta paradoja, haciendo que el matrimonio dure mientras se vive paralelamente una relación apasionada.
La originalidad del libro de Garcia es que presenta las relaciones clandestinas durables no solo como derivaciones no buscadas del matrimonio, y mucho menos como resultados de desvíos patológicos, sino como parte de un sistema de interdependencia con él. Se trata de un ensayo que plantea claves para pensar un tipo de socialización afectiva secundaria de la que poco se habla aunque muchas personas la habiten. Un libro que invita a generar estudios locales y que además, tal como hizo Eva Illouz con su ensayo sobre el sufrimiento amoroso, le disputa el campo a la literatura de autoayuda, confirmando que las ciencias sociales resultan imprescindibles para la comprensión del mundo, en este caso, para abordar ese "jardín secreto" - como llaman a esta esfera de la intimidad en Francia- del amor, la sexualidad y el erotismo. 
